\title{
Superscan Imaging on Ga-68 PSMA PET/CT in Prostate Cancer Patient
}

Sait Sager ${ }^{\star}$, Elife Akgun, Onur Erdem Şahin, Burak Akgun and Kerim Sonmezoglu

Department of Nuclear Medicine, Istanbul University Cerrahpasa Medical Faculty, Cerrahpasa, Fatih, Istanbul, Turkey

*Corresponding author: Sait Sager, Department of Nuclear Medicine, Istanbul University, Cerrahpasa Medical Faculty, Cerrahpasa, Fatih, Istanbul, Turkey, Tel: +90 212 414 3000, 9021241422984; Fax: +90 212530 8055; E-mail: saitsager@yahoo.com

Received date: November 13, 2016; Accepted date: December 03, 2016; Published date: December 06, 2016

Copyright: (c) 2017 Sager S, et al. This is an open-access article distributed under the terms of the Creative Commons Attribution License, which permits unrestricted use, distribution, and reproduction in any medium, provided the original author and source are credited.

Citation: Sager S, Akgün E, Sahin OE, Akgün B, Sönmezoglu K (2017) Superscan Imaging on Ga-68 PSMA PET/CT in Prostate Cancer Patient. J Nucl Med Radiat Ther 8: 320. doi:10.4172/2155-9619.1000320

\begin{abstract}
Prostate cancer $(\mathrm{PCa})$ is the most frequent tumor in men worldwide. PCa bone metastasis is mainly osteosclerotic, and is caused by a relative excess of osteoblast activity. A superscan on Tc-99m bone scintigraphy is described in multiple skeletal metastatic disease. Prostate-specific membrane antigen (PSMA) is a cell surface protein with high expression in prostate carcinoma cells. Ga-68 labelled PSMA imaging is used for staging and to evaluate the most appropriate therapy.
\end{abstract}

Keywords: Prostate cancer; Ga-68 PSMA; Superscan

\section{Case Report}

Prostate cancer $(\mathrm{PCa})$ is the most frequent tumor in men worldwide and prostate cancer most often spreads to bone, commonly leading to bone pain [1]. PCa bone metastasis is mainly osteosclerotic, and is caused by a relative excess of osteoblast activity. A superscan on Tc-99m bone scintigraphy is described in multipl skeletal metastatic disease [2].

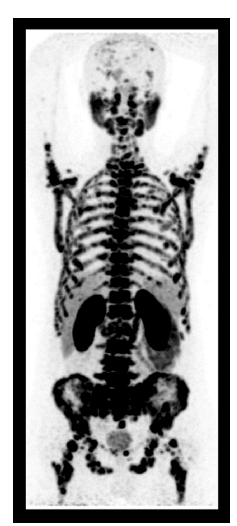

Figure 1: Superscan showing extensive and intense skeletal uptake in the axial and appendicular skeleton.

Prostate-specific membrane antigen (PSMA) is a cell surface protein with high expression in prostate carcinoma cells. Ga-68 labelled PSMA imaging is used for staging and to evaluate the most appropriate therapy [3]. We want to share Ga-68 PSMA PET/CT imaging of a 67year-old prostate cancer patient. He had a radical prostatectomy after diagnosed $\mathrm{PCa}$ with biopsy. His pathology reported as adenocarcinoma with gleason score $4+3=7$. Ga-68 PSMA imaging demonstrated extensive and intence skeletal uptake in the axial and appendicular skeleton which is called superscan imaging (Figure 1).

Superscan was also described in F-18 FDG PET/CT imaging in extensive metastatic cancer [4]. Vertex to middle femur imaging was performed $60 \mathrm{~min}$ after injection of $4 \mathrm{mci}$ Ga-68 PSMA when current total PSA value was $120.06 \mathrm{ng} / \mathrm{ml}$. There is no regional recurrence or lymph node metastasis but multiple sclerotic and lytic lesions with extensive and diffuse uptake at skeleton system (Figure 2).

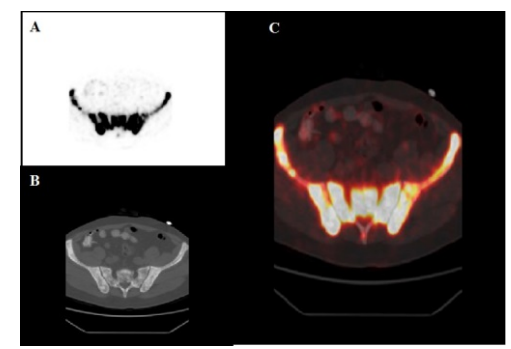

Figure 2: Axial pelvis PET, CT and Fusion images.

\section{References}

1. Ibrahim T, Flamini E, Mercatali L, Sacanna E, Serra P, et al. (2010) Pathogenesis of osteoblastic bone metastases from prostate cancer. Cancer 116: 1406-1418.

2. Buckley O, O'Keeffe S, Geoghegan T, Lyburn ID, Munk PL, et al. (2007) 99mTc bone scintigraphy superscans: A review. Nucl Med Commun 28: 521-527.

3. Afshar-Oromieh A, Malcher A, Eder M, Eisenhut M, Linhart HG, et al. (2013) PET imaging with a [68Ga]gallium-labelled PSMA ligand for the diagnosis of prostate cancer: biodistribution in humans and first evaluation of tumour lesions. Eur J Nucl Med Mol Imaging 40: 486-495.

4. Bailly M, Besse H, Kerdraon R, Gilles M, Sabine G (2014) 18F-FDGPET/ CTsuperscan in prostate cancer. Clin Nucl Med 39: 912-914. 